\title{
Effect of adding dexamethasone to lidocaine on the quality of intravenous regional anesthesia for upper extremity orthopedic operations: A randomized clinical trial
}

\author{
Abbas Moallemy ${ }^{1}$, Hashem Jarineshin ${ }^{2}$, Fereydoon Fekrat ${ }^{3}$, Alireza Abdullahzadeh Baghaaei ${ }^{1}$, Manuchehr \\ Kamali $^{3}$, Bibi Mona Razavi ${ }^{4}$, Zobeir Shaerzadeh ${ }^{5}$
}

${ }^{1}$ MD, Assistant Professor of Anesthesiology, Pain Management Fellowship, Anesthesiology, Critical Care and Pain Management Research Center, Hormozgan University of Medical Sciences. Bandar Abbas, Iran

${ }^{2} \mathrm{MD}$, Associate Professor of Anesthesiology, Cardiac and Thoracic Anesthesia Fellowship, Anesthesiology, Critical Care and Pain Management Research Center, Hormozgan University of Medical Sciences. Bandar Abbas, Iran

${ }^{3}$ MD, Anesthesiology Specialist, Anesthesiology, Critical Care and Pain Management Research Center, Hormozgan University of Medical Sciences. Bandar Abbas, Iran

${ }^{4}$ MD, Anesthesiology Resident, Anesthesiology, Critical Care and Pain Management Research Center, Hormozgan University of Medical Sciences. Bandar Abbas, Iran

${ }^{5}$ MD, Assistant Professor of Surgery, Anesthesioligy, Critical care and Pain Management Research Center, Hormozgan University of Medical Sciences. Bandar Abbas, Iran

Type of article: Original

\begin{abstract}
Background: Intravenous regional anesthesia (IVRA) is an ideal technique for short surgery on the distal extremities. Different additives have been used to improve lidocaine's block quality.

Objective: The aim of this study was to determine the effect of adding dexamethasone to lidocaine on improving the quality of IVRA.

Methods: This study is a prospective, double-blind randomized study which was done on patients with upper extremity injuries of the distal elbow in Shahid Mohammadi Hospital, Bandar Abbas from October 2014 to December 2015. A total of 110 patients aged 15 to 65 years, with ASA class I and II, with orthopedic injuries distal to the elbow, were randomly divided into two groups. The control group (L) and the intervention group $(\mathrm{L}+\mathrm{D})$ received a $40-\mathrm{ml}$ solution of $3 \mathrm{mg} / \mathrm{kg}$ lidocaine, and $3 \mathrm{mg} / \mathrm{kg}$ lidocaine $+8 \mathrm{mg}$ of dexamethasone respectively. The two groups were compared in terms of onset and recovery time of sensory block in each of the dermatome nerves classified as radial, ulnar, and median, vital signs, patient satisfaction, intraoperative opioid consumption, and request for the first postoperative opioid.
\end{abstract}

Results: There was no significant difference between the two groups in terms of demographic characteristics. Mean arterial blood pressure was higher in the $\mathrm{L}+\mathrm{D}$ group $(100.39 \pm 14.6 \mathrm{mmHg})$ in comparison to the $\mathrm{L}$ group $(90.50 \pm 11 \mathrm{mmHg})(\mathrm{p}=0.002)$. Need for opioid was reported in $20(35.7 \%)$ patients in the $\mathrm{L}+\mathrm{D}$ group in comparison to $17(31.5 \%)$ in the L group $(\mathrm{p}=0.639)$. The average intraoperative dose of fentanyl was $95 \pm 32.04$ $\mathrm{mcg}$ and $88.44 \pm 18.77 \mathrm{mg}$ in $\mathrm{L}+\mathrm{D}$ and $\mathrm{L}$ groups respectively and there was no significant difference between the two groups in this respect $(\mathrm{p}=0.479)$. In addition, the average dose of pethidine administered in the recovery room for $\mathrm{L}+\mathrm{D}$ group $(19.34 \pm 15.22) \mathrm{mg}$ was significantly higher than in the $\mathrm{L}$ group $(9.44 \pm 12.26 \mathrm{mg})(\mathrm{p}=0.001)$.

Conclusions: Adding $8 \mathrm{mg}$ dexamethasone to lidocaine has no effect on IVRA solution in upper extremity orthopedic operations and also increases postoperative opioid consumption.

Trial registration: The trial was registered at the Iranian Registry of Clinical Trials (http://www.irct.ir) with the Irct ID: IRCT2016052928158N1.

Funding: The authors received financial support from Hormozgan University of Medical Sciences.

Keywords: Lidocaine, Additive, Dexamethasone, Upper extremity

\section{Corresponding author:}

Dr. Bibi Mona Razavi, Anesthesiology, Critical Care and Pain Management Research Center, Shahid Mohammadi Hospital, Hormozgan University of Medical Sciences, Jomhouriye Eslami Boulevard, Bandar Abbas, Postal Code: 7919915519, Iran. Tel: +98.9171671800, Fax:+98.7633345009, Email: razavi.b.m.1@gmail.com

Received: April 11, 2017, Accepted: August 30, 2017, Published: April 2018

iThenticate screening: August 31, 2017, English editing: February 25, 2018, Quality control: March 12, 2018

This article has been reviewed / commented by three experts

(C) 2018 The Authors. This is an open access article under the terms of the Creative Commons Attribution-NonCommercialNoDerivs License, which permits use and distribution in any medium, provided the original work is properly cited, the use is non-commercial and no modifications or adaptations are made. 


\section{Introduction}

\subsection{Background}

Intravenous regional anesthesia (IVRA) or Biers block is an effective anesthetic technique used in upper and lower extremity surgeries. This method induces surgical anesthesia through intravenous injection of a local anesthetic (LA) substance in to a limb, the blood flow of which is blocked by a tourniquet. Lidocaine is the local anesthetic agent widely used for IVRA $(1,2)$, and is the only anesthetic approved by the FDA for intravenous regional anesthesia. Lidocaine spreads widely, inducing a fast and robust regional anesthesia, the lower and higher concentrations of which, respectively affect nerve endings and the nerve trunks along with nerve endings (1). However, generally three constraints have been described for IVRA: relatively slow onset of action, tourniquet pain, and lack of postoperative analgesia. For this reason, its use has been limited to short duration surgeries on distal extremities (35). Other disadvantages of IVRA are, local anesthetic toxicity and post-tourniquet period of rapidly evolving pain, due to lack of postoperative analgesia (6).

\subsection{Statement of problem}

In order to achieve an ideal block quality, IVRA solution must create the following conditions: rapid onset of action, reduced dose of local anesthetic, reducing tourniquet pain, and long-lasting analgesic effect after tourniquet deflation $(4,7)$. For the purpose of gaining these properties, different applications have been implicated, such as adding adjuvants including; nonsteroidal anti-inflammatory drugs, alpha 2 agonists, opioids, tramadol, ketamine, dexamethasone, nitroglycerin, butorphanol, muscle relaxing agents, neostigmine, magnesium, sodium bicarbonate, potassium, or other methods such as gabapentin pretreatment and changing local anesthetic $(4,8,9)$. Dexamethasone is a long-acting glucocorticoid, and induces anti-inflammatory and immune suppression effects. Although its mechanism of action is not fully understood as an adjuvant, it has been shown that it applies its anti-inflammatory and analgesic effects by inhibiting phospholipase A2 and activation of glucocorticoid receptors (10). It reduces inflammation by stabilizing leukocyte lysosomal membrane, preventing macrophage accumulation in inflamed areas and reducing capillary wall permeability and edema formation (11). Akram et al. have shown in their study that adding dexamethasone and ketorolac to lidocaine increases the patients' tourniquet tolerance in forearm and hand surgeries (12). Several other agents are used as an adjuvant therapy to lidocaine to improve its effect (13-16). Bigat et al. have reported that adding dexamethasone to lidocaine improves the quality of post-operative analgesia in patients who have undergone hand surgeries (14). Also, Biradar et al. have reported earlier onset of blockade and longer duration of block by adding dexamethasone to lidocaine (17). More studies are needed for determination of the effect of dexamethasone added to lidocaine and also its side effects in upper extremity surgeries.

\subsection{Objectives}

The aim of this study was to evaluate the effect of adding dexamethasone to lidocaine on the quality of Bier block in upper extremity orthopedic surgeries (distal to the elbow).

\section{Material and Methods}

\subsection{Trial design}

This study is a prospective, double-blind clinical interventional trial. The study population consisted of the 15-65 years old patients (in ASA class I and II, with upper extremity injuries of the distal elbow) who were referred to the orthopedic operating room of Shahid Mohammadi Hospital, Bandar Abbas from October 2014 to December 2015.

\subsection{Participants and selection criteria}

Inclusion criteria were: aged between 15 and 65 years and distal upper extremity orthopedic elbow injury. ASA class III and IV patients, as well as individuals with myasthenia gravis, scleroderma, Reynolds disease, sickle cell, diabetes mellitus, neuropathy, a history of sensitivity to lidocaine or dexamethasone and patients with extensive injury not suitable for Biers block and those who needed intra-operative general anesthesia due to adverse events during IVRA were excluded from the study.

\subsection{Research ethics}

Informed consent was obtained from all patients on the basis of the Helsinki Treaty with the approval of the Ethics Committee of Hormozgan University of Medical Sciences (HUMS. REC. 1394.95). The trial was registered at the Iranian Registry of Clinical Trials (http://www.irct.ir) with the Irct ID: IRCT2016052928158N1. 


\subsection{Sample size}

Based on previous research (1), an average increase of 3 minutes was expected in the duration of sensory block in cases of using dexamethasone, and the least sample size of 50 individuals were obtained in each group based on this expectation, and test power of $90 \%$ and the sample size formula used in clinical trials.

\subsection{Randomization}

Patients were assigned to two groups according to a block randomization table. In other words, all eligible patients were divided into lidocaine $(\mathrm{L})$ or $\mathrm{L}+$ dexamethasone $(\mathrm{L}+\mathrm{D})$ groups based on their entry into the orthopedic operation room department of Shahid Mohammadi Hospital, Bandar Abbas (Figure 1).

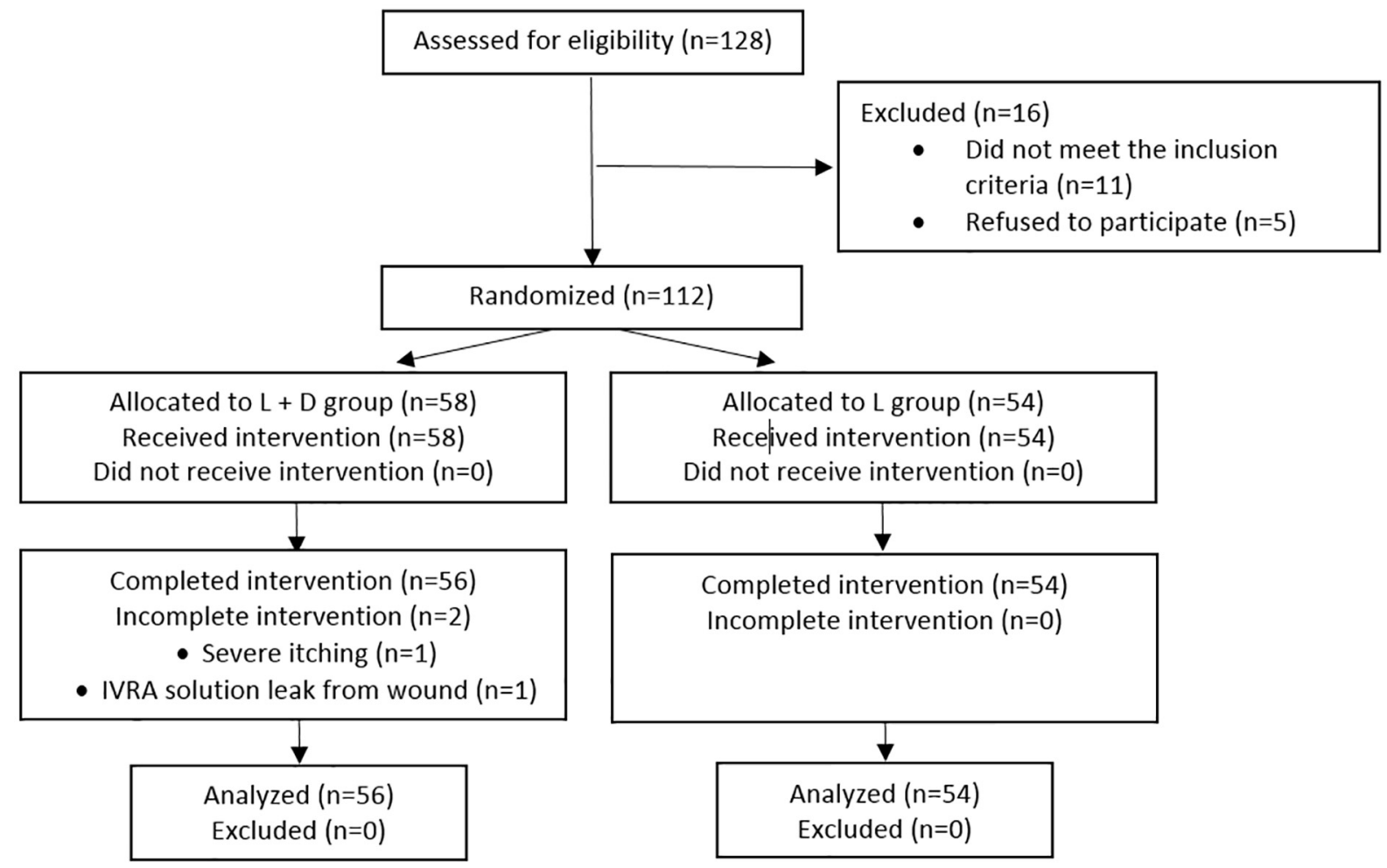

Figure 1. Consort diagram of the study. L: Lidocaine, D: Dexamethasone

\subsection{Outcomes}

The primary outcomes of this study were; the onset and duration of sensory block, the level of patients' satisfaction, intraoperative opioid consumption, and request for the first postoperative opioid (after tourniquet deflation).

\subsection{Interventions}

Demographic variables of all studied patients were initially recorded and all patients underwent the monitoring (Vector Monitor device, Sazgan, Sazgan Gostar Co., Tehran, Iran) of ECG, noninvasive arterial blood pressure, pulse oximetry and heart rate. Baseline vital signs were recorded 5 and 20 minutes after tourniquet inflation, immediately after tourniquet deflation, and during the recovery room period. An intravenous cannula was inserted into the most distal part of the limb to be operated. Also, a separate intravenous cannula was inserted into the other upper limb for the infusion of fluids and injection of other medications. A double tourniquet (Rs3000, Raeen Sanat Co., Tehran, Iran) was fastened on a layer of cotton band, above the elbow of the intended limb. After draining the blood from the extremities by limb elevation and closing tightly with the rubber esmarch band from the fingertips to the elbow, the proximal cuff was inflated approximately $150 \mathrm{~mm} \mathrm{Hg}$ higher than the systolic blood pressure and lack of radial pulse was considered as a sign of sufficient tourniquet pressure. The IVRA local anesthetic solution containing $3 \mathrm{mg} / \mathrm{kg}$ lidocaine ( $2 \%$ Lidocaine ampule, Caspian Tamin Pharmaceutical Co., Rasht, Iran) was diluted to a volume of $40 \mathrm{ml}$ using distilled water and injected slowly over 2 minutes. The intervention group received the above anesthetic solution along with $8 \mathrm{mg}$ dexamethasone (2 cc Dexamethasone ampule, Darou Pakhsh Pharmaceutical Co., Tehran, Iran). Intra and post-operative assessments and data documentation were carried out by 
an anesthesiology resident who was unaware of the categories and randomization of the groups. After the injection of the anesthetic solution, the sensory block was separately checked and recorded in the radial, ulnar and median nerve pathways (by pinprick test with needle gauge No. 22) every 30 seconds. In addition, all patients received $2 \mathrm{mg}$ of intravenous midazolam. After the onset of tourniquet pain, the distal cuff that was placed on the numbed skin was inflated and the proximal cuff was deflated. Afterwards, $1 \mu / \mathrm{kg}$ fentanyl was administered intravenously in cases of continued pain and NRS above 3, and in the absence of pain relief, the same dose of fentanyl was administrated once again. Time and intake of intraoperative opioid was recorded. Patient satisfaction (13) was recorded as follows: 1- Excellent: No pain, 2- Good: Brief complaints without the need for medication, 3 - Moderate pain and the need for analgesic adjuvant ( $1 \mu / \mathrm{kg}$ fentanyl IV), 4- The need for sedation: Intravenous dose of propofol sedation (25 to 75 $\mu / \mathrm{kg} /$ minute) was administered to patients who still had discomfort after receiving 2 doses of fentanyl $(1 \mu / \mathrm{kg})$, and 5- The non-successful group that required general anesthesia due to failure in IVRA block and sedation (fentanyl and propofol) and was excluded from the study. Tourniquet pressure was deflated gradually, at least 25 minutes after injection of anesthetic solution. The duration of the surgical procedure was recorded in minutes. The sensory recovery time was recorded in the same way using pinprick with needle gauge No. 22 after deflating the cuff every 30 seconds. Throughout this process, patients were monitored for the occurrence of allergy symptoms and medication toxicity. The time of request for the first postoperative opioid was recorded (tourniquet cuff deflation until the request for the first postoperative opioid based on minutes). In cases of NRS score of more than 3, meperidine $25 \mathrm{mg}$ (Pethidine $2 \mathrm{~mL}$ ampule, Caspian Tamin Pharmaceutical Co., Rasht, Iran) was initially injected intravenously and was repeated once again in cases of continued pain. (Each patient was monitored during the recovery for 1 hour).

\subsection{Statistical analysis}

All data were analyzed with IBM( $\odot$ SPSS $\odot$ Statistics version 20 (IBM $\odot$ Corp., Armonk, NY, USA). Descriptive statistics such as mean, standard deviation, frequency and relative frequency were used for descriptive data analysis. Statistical methods, including Independent samples t-test and chi-square test were used to compare the dependent variables in two groups. Significance level of 0.05 was considered significant in all comparative tests. KolmogorovSmirnov test was used to assess the normality of quantitative variables between the two groups in a way that if a quantitative variable in both groups was normally distributed, the Independent samples t-test was used, and if there was not such a case, the Mann-Whitney test was used.

\section{Results}

In this study, 128 patients were recruited and 112 patients were allocated to the two groups (Figure 1). Two individuals (both from L + D Group) were excluded, one due to severe and uncontrollable itching in the anesthetized limb and the other one due to anesthetic solution releasing out of a massive forearm wound. There were no significant differences between $\mathrm{L}$ and $\mathrm{L}+\mathrm{D}$ groups in terms of demographic variables such as age, height, weight and BMI, as well as underlying variables such as gender, type of surgery and the ASA class and the surgery duration (Table 1). There was no significant difference between $\mathrm{L}$ and $\mathrm{L}+\mathrm{D}$ groups in terms of systolic, diastolic blood pressure and mean arterial pressure base line, 5 and 20 minutes after the start of surgery and immediately after tourniquet deflation. But the mean arterial blood pressure during recovery was $100.39 \pm 14.60 \mathrm{~mm} \mathrm{Hg}$ and $90.50 \pm 11.00 \mathrm{~mm} \mathrm{Hg}$ in the intervention and control groups, respectively, which significantly had higher values $(\mathrm{p}=0.002)$ in the intervention group $(\mathrm{L}+\mathrm{D})$ (Figure 2). There was no significant difference between $\mathrm{L}$ and $\mathrm{L}+\mathrm{D}$ groups in terms of average heart rate during surgery, 5 and 20 minutes after the start of surgery, and immediately after recovery and tourniquet deflation (Figure 3 ). A total of 36 patients $(64.3 \%)$ in the $\mathrm{L}+\mathrm{D}$ Group did not receive intraoperative opioid, and 20 patients (35.7\%) needed the opioid, compared to the L Group, 37 cases (68.5\%) of which did not receive intraoperative opioid and 17 patients (31.5\%) required intraoperative opioid. Also, there was no significant difference between the two groups in terms of the variable of number of individuals who needed the intraoperative opioid (opium requirement) $(\mathrm{p}=0.639)$. The average intraoperative dose of fentanyl was $95 \pm 32.04$ $\mathrm{mcg}$ and $88.44 \pm 18.77 \mathrm{mg}$ in $\mathrm{L}+\mathrm{D}$ and $\mathrm{L}$ groups respectively, and there was no significant difference between the two groups in this respect $(\mathrm{p}=0.479)$. Average intraoperative patient satisfaction was $1.84 \pm 1.09$ and $1.84 \pm 1.19$ in the in $\mathrm{L}+\mathrm{D}$ and $\mathrm{L}$ groups and there was no difference between the two groups in this regard. In this study, satisfaction level 1 (excellent) was $62.6 \%$, which was higher than the other levels of overall satisfaction. Also, there was no significant difference between the two groups in terms of variable of levels of satisfaction (Table 2). Onset time and recovery of sensory block in each nerve (radial, median, and ulnar) was comparable in both $\mathrm{L}+\mathrm{D}$ and $\mathrm{L}$ groups and there was no significant difference between the two groups in this regard (Table 3). There was a significant difference between the two groups in terms of the need for postoperative opioid use (L + D) Group 64.3\% vs. 31.5\% in the L Group ( $\mathrm{p}=0.001)$. In other words, the opioid drug was consumed more in the $\mathrm{L}+\mathrm{D}$ Group during the 
recovery as compared with the L Group. In addition, the average dose of pethidine administered in the recovery room for $\mathrm{L}+\mathrm{D}$ and $\mathrm{L}$ groups was $19.34 \pm 15.22 \mathrm{mg}$ and $9.44 \pm 12.26 \mathrm{mg}$, respectively. Thus, mean dose of pethidine was significantly higher $(p=0.001)$ in the $\mathrm{L}+\mathrm{D}$ group than the control group. Moreover, there was no significant difference between the two groups in terms of the mean time of the request for the first postoperative opioid $(\mathrm{L}+\mathrm{D}=12.94 \pm 6.92$ minutes and $\mathrm{L}=16.19 \pm 13.70$ minutes) $(\mathrm{p}=0.764)$. In this study, a total of 5 patients suffered from an itching complication in the $\mathrm{L}+\mathrm{D}$ group and one of them were excluded from the study due to the severity of itching. Also, there was no significant difference between the two groups based on Fisher's exact test in this regard $(\mathrm{p}=0.118)$.

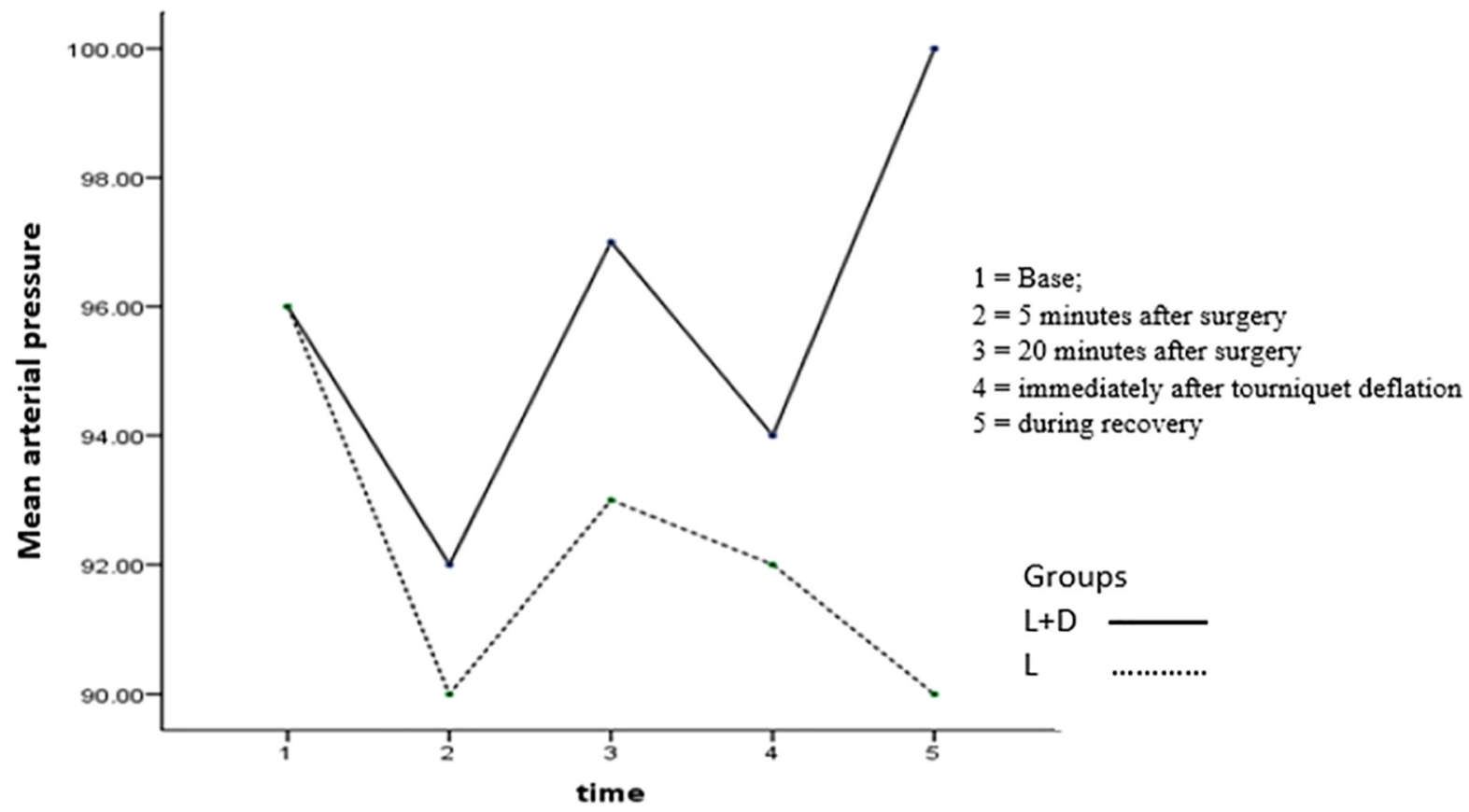

Figure 2. Comparing mean arterial pressure between intervention and control groups at 5 time points.

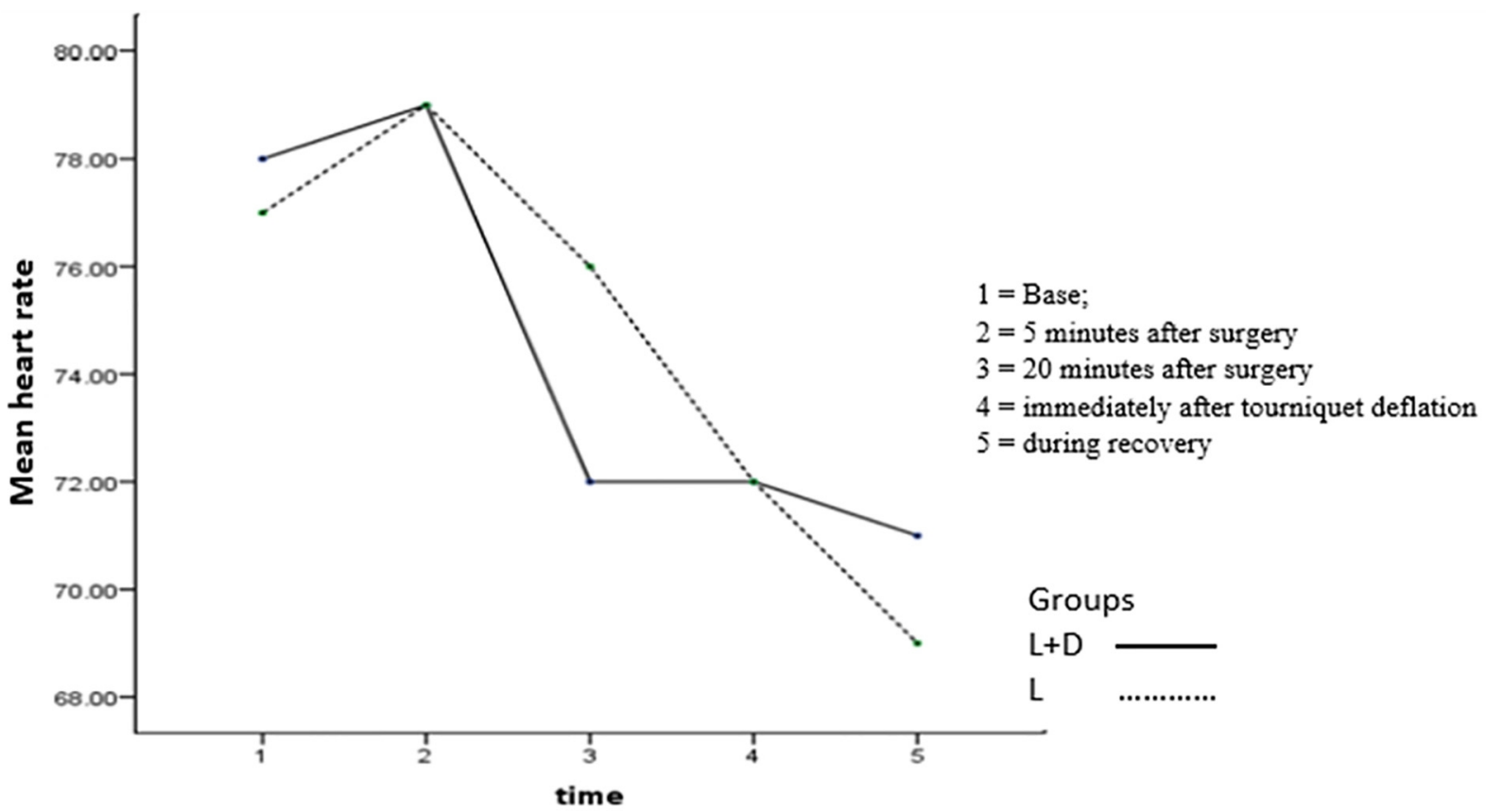

Figure 3. Comparing the heart rate between the intervention and control groups at five time points 
Table 1. Demographic data of the two groups, lidocaine and lidocaine + dexamethasone

\begin{tabular}{|c|c|c|c|c|c|c|}
\hline \multirow{2}{*}{\multicolumn{2}{|c|}{ Variables }} & \multicolumn{2}{|c|}{ Group (Mean \pm SD) / n (\%) } & \multirow[t]{2}{*}{ Test statistics } & \multirow[t]{2}{*}{ Degrees of freedom } & \multirow[t]{2}{*}{$\mathrm{p}$-value } \\
\hline & & $\mathrm{L}+\mathrm{D}$ & $\mathrm{L}$ & & & \\
\hline \multicolumn{2}{|l|}{ Age (years) } & $29.84 \pm 11.30$ & $33.43 \pm 14.63$ & $-1.029^{a}$ & --------- & 0.303 \\
\hline \multicolumn{2}{|l|}{ Height $(\mathrm{cm})$} & $170.50 \pm 8.12$ & $170.41 \pm 8.08$ & $-0.178^{a}$ & --------- & 0.858 \\
\hline \multicolumn{2}{|l|}{ Weight (kg) } & $70.41 \pm 14.35$ & $71.28 \pm 15.52$ & $-0.304^{\mathrm{b}}$ & 108 & 0.761 \\
\hline \multicolumn{2}{|l|}{ BMI $\left(\mathrm{kg} / \mathrm{m}^{2}\right)$} & $23.64 \pm 3.73$ & $24.35 \pm 4.56$ & $-0.609^{a}$ & --------- & 0.542 \\
\hline \multicolumn{2}{|c|}{ Duration of surgery (minute) } & $45.19 \pm 15.30$ & $43.30 \pm 13.75$ & $-0.295^{a}$ & --------- & 0.768 \\
\hline \multirow[t]{2}{*}{ Gender } & Male & $47(83.9)$ & $50(92.6)$ & \multirow[t]{2}{*}{$1.980^{\mathrm{c}}$} & \multirow[t]{2}{*}{1} & \multirow[t]{2}{*}{0.159} \\
\hline & Female & $9(16.1)$ & $4(7.4)$ & & & \\
\hline \multirow[t]{2}{*}{ Surgery type } & 1 & $43(76.8)$ & $41(75.9)$ & \multirow[t]{2}{*}{$0.011^{\mathrm{c}}$} & \multirow[t]{2}{*}{1} & \multirow[t]{2}{*}{0.915} \\
\hline & 2 & $13(23.2)$ & $13(24.1)$ & & & \\
\hline \multirow[t]{2}{*}{ ASA } & $\mathrm{I}$ & $49(87.5)$ & $45(83.3)$ & \multirow[t]{2}{*}{$0.384^{\mathrm{c}}$} & \multirow[t]{2}{*}{1} & \multirow[t]{2}{*}{0.535} \\
\hline & II & $7(12.5)$ & $9(16.7)$ & & & \\
\hline
\end{tabular}

A: Mann-Whitney Test, b: t-test, c: Chi-square; Surgery type 1: Hand surgery; Surgery type 2: Forearm surgery

Table 2. Comparison of different levels of satisfaction between the two groups

\begin{tabular}{|l|l|l|l|l|}
\hline \multirow{2}{*}{ Level of patient satisfaction } & Group & L & Total & p-value \\
\cline { 2 - 4 } & L+D & \multicolumn{2}{|l|}{0.427} \\
\hline 1 & $60.7 \%(\mathrm{n}=34)$ & $68.5 \%(\mathrm{n}=37)$ & $64.5 \%(\mathrm{n}=71)$ & \\
\hline 2 & $1.8 \%(\mathrm{n}=1)$ & $0.0 \%(\mathrm{n}=0)$ & $0.9 \%(\mathrm{n}=1)$ \\
\hline 3 & $30.4 \%(\mathrm{n}=17)$ & $18.5 \%(\mathrm{n}=10)$ & $24.5 \%(\mathrm{n}=27)$ \\
\hline 4 & $7.1 \%(\mathrm{n}=4)$ & $13.7 \%(\mathrm{n}=7)$ & $10.3 \%(\mathrm{n}=11)$ \\
\hline Total & $100.0 \%(\mathrm{n}=56)$ & $100.0 \%(\mathrm{n}=54)$ & $100.0 \%$ & \\
\hline
\end{tabular}

Table 3. The mean onset and recovery time of sensory block in radial, ulnar and median nerves in the intervention and control groups.

\begin{tabular}{|c|c|c|c|c|c|c|c|}
\hline \multicolumn{2}{|l|}{ Based on minutes } & \multicolumn{4}{|l|}{ Group } & \multirow{4}{*}{$\begin{array}{l}\text { Test } \\
\text { statistics }^{\mathrm{a}} \\
-1.118\end{array}$} & \multirow{4}{*}{$\begin{array}{l}\text { p-value } \\
0.263\end{array}$} \\
\hline & & \multicolumn{2}{|l|}{$\mathrm{L}+\mathrm{D}$} & \multicolumn{2}{|l|}{$\mathrm{L}$} & & \\
\hline & & Mean & SD & Mean & SD & & \\
\hline \multirow[t]{2}{*}{ Radial. N (minute) } & Onset & 0.77 & 1.41 & 1.01 & 1.53 & & \\
\hline & Recovery & 2.45 & 1.66 & 2.78 & 3.29 & -0.445 & 0.657 \\
\hline \multirow[t]{2}{*}{ Ulnar. N (minute) } & Onset & 0.72 & 1.32 & 1.01 & 1.68 & -1.037 & 0.300 \\
\hline & Recovery & 1.80 & 1.59 & 2.79 & 2.79 & -1.903 & 0.057 \\
\hline \multirow[t]{2}{*}{ Median. N (minute) } & Onset & 0.69 & 0.90 & 1.12 & 1.85 & -0.691 & 0.490 \\
\hline & Recovery & 1.98 & 1.71 & 3.22 & 4.97 & -1.349 & 0.177 \\
\hline
\end{tabular}

a: Mann-Whitney Test

\section{Discussion}

In this study, the onset of sensory block was separately evaluated and recorded for each of the radial, ulnar, and median nerves and there was no significant difference between the $\mathrm{L}+\mathrm{D}$ and $\mathrm{L}$ groups in terms of mean onset and recovery time of sensory block variable in each of the three radial, ulnar and median nerves based on the statistical analysis. In line with our results, other studies showed no significant differences in terms of onset of sensory block $(1,14,15)$ after adding dexamethasone to lidocaine. This finding also confirms our results on the lack of effect of dexamethasone on the onset of sensory block of radial, ulnar and median nerves. But a recent study, paradoxically showed that the median onset time of sensory block was significantly shorter in the L + D Group (2.69 \pm 1.13 minutes) compared with the L Group (4.02 \pm 1.13 minutes) (16). In our study, onset of sensory block of each radial $(0.77 \pm 1.41$ minutes in L $+\mathrm{D}$ Group, and $1.01 \pm 1.53$ minutes in L Group), ulnar $(0.72 \pm 1.32$ minutes in $\mathrm{L}+\mathrm{D}$ Group, $1.01 \pm 1.68$ minutes in L Group), and median ( $0.69 \pm 0.90$ minutes in $\mathrm{L}+\mathrm{D}$ Group, and $1.12 \pm 1.85$ minutes in $\mathrm{L}$ Group) dermatomes were shorter compared with those obtained in the study of Hassani et al. (16). However, it should be noted that although the sensory dermatomes of radial, ulnar and median nerves have been evaluated in all the studies mentioned above, the onset and recovery of sensory block of these nerves had not been recorded separately; thus, we could not find separate resources for each of the nerves. Therefore, this maybe the first study to record this variable for each nerve dermatome separately. Adding dexamethasone in to the local anesthetic solution 
can show a different effect in relation to the type of regional block for which it is used. In this regard, Biradar et al. (17) showed that the supraclavicular block in $1.5 \%$ lidocaine $(7 \mathrm{mg} / \mathrm{kg})+$ dexamethasone $(2 \mathrm{~mL}=8 \mathrm{mg})$ Group was associated with a faster onset of action, contrary to our findings and those obtained in other studies in the field of Bier block $(1,14,15)$. Additionally, in the Biradar et al. study (17), adrenaline was added to the anesthetic solution for supracalvicular block which is contraindicated for Bier's block, although, it has been shown that adrenaline has no effect on the onset of the blockade (18). Furthermore, the present study showed that there is no significant difference between the two groups in terms of onset and recovery of sensory block for each radial, ulnar dermatomal region. In line with our results, Jankovic et al. (15) found no significant difference between groups in terms of mean time to recovery of sensory block. Paradoxically, in another similar study, Amin et al. (1) reported that the recovery time of sensory and motor block was prolonged in the intervention group who received $8 \mathrm{mg}$ dexamethasone as an adjuvant to the IVRA anesthetic solution (1). Similarly, Bigat et al. also reported that the sensory block recovery time was significantly prolonged in the intervention group who received $8 \mathrm{mg}$ dexamethasone adjuvant to IVRA anesthetic solution compared with the lidocaine control group (14). We found no other large study or meta-analysis on the recovery of sensory block after Bier block. However, a meta-analysis study that was carried out on 9 studies and 801 patients with brachial plexus block, which showed that the addition of dexamethasone to local anesthetics in peripheral brachial plexus block, significantly prolonged sensory and motor block (19). The findings of the above studies $(1,14,19)$ on the sensory block recovery variable, are inconsistent with the findings of the present study. In the present study, there was no significant difference between the two groups in terms of the satisfaction variable. We could not find any studies related to the patient satisfaction variable on dexamethasone lidocaine combination in IVRA. There was no significant difference between the two groups with regard to the number of patients who needed intra-operative opioids. Also, there was no significant difference between the two groups in terms of the dose of intraoperative opioid which is consistent with the study of Bigat et al., in which the intraoperative dose of systemic fentanyl used to relieve the tourniquet pain was similar between groups (14). However, Hassani et al. showed that the need for intraoperative fentanyl in the L+D Group is significantly lower than the control group (16). Our results also showed that there was no significant difference between the two groups in terms of time of the request for the first post-operative opioid $(\mathrm{p}=0.764)$. However, the average time of the request for the first postoperative opioid was $12.94 \pm 6.92$ minutes in the $\mathrm{L}+\mathrm{D}$ Group, which is less than the same time in the control group (16.19 \pm 13.70 minutes), but this difference was not statistically significant. Only one study which was conducted by Bigat et al. showed that the time of request for the first post-operative opioid was shorter in the L+D Group than the other groups (14). The results of the present study showed that the number of individuals who needed the postoperative opioid as well as the drug dose was significantly increased $(\mathrm{p}=0.001)$ in the intervention group $(\mathrm{L}+\mathrm{D}$ Group) than the control group (19.34 $\pm 15.22 \mathrm{mg}$ pethidine vs. $9.44 \pm 12.26 \mathrm{mg}$ pethidine in L Group) which is inconsistent with the findings of other studies $(1,14,16)$. However, it is noteworthy that since the subjects had undergone outpatient surgery, they were monitored for only a short time (1 hour) during the recovery, therefore, it was impossible to prescribe the opioid at home and monitor its use. But most similar previous studies have calculated the mean opioid consumption in longer postoperative periods, which is perhaps one of the reasons for the inconsistency of our results with the mentioned studies $(1,14,16)$. Itching was the only complication observed in this study, in which 5 patients suffered from localized itching in injected limb distal to the tourniquet in the L+D Group, and only one of them was excluded due to severe itching. However, this complication was mild in 4 patients. None of the patients had this itching complication in the control group. This complication has not been reported in other studies which had used L+D for IVRA block limbs $(1,14,16)$. Non-invasive arterial blood pressure, systolic and diastolic pressure and mean arterial blood pressure were significantly higher in the L+D Group in postanesthesia care unit (PACU) than the control group. While there was no significant difference between the two groups in terms of this variable in other time points before PACU period. Higher blood pressure in the L+D Group can be attributed to dexamethasone side effects. This finding limits its use in anesthesia of the patients. Also, it should be considered that higher blood pressure in the L $+\mathrm{D}$ group may be due to ineffective blockade of the nerves, and does not support the use of dexamethasone in the addition of lidocaine for limb block. Noticeably, the heart rate variable did not show any significant difference between the two groups throughout the study period. Additionally, the hemodynamic parameters have not been studied in previous studies conducted on L+D for limb IVRA blockade, and it seems that measurement and the results of this study may be valuable with regard to the relationship between hemodynamic changes and the need for further opioid due to the possibility of more postoperative pain. Our trial had some limitations. We had not measured the quality of motor block in our study samples. It can be considered for future studies. We were also unable to consider long-term side effects of treatment. However, it seems that there is no long-term side effect for the patients but it should be considered in future studies. The effects of different dexamethasone and lidocaine doses were not observed in this study. 


\section{Conclusions}

Generally, based on the findings and results of the present study, it seems that the addition of dexamethasone to lidocaine anesthetic solution of IVRA not only has no positive effect on the quality of Bier block, but also, it will lead to an increase in postoperative opioid consumption. We recommend not to add dexamethasone to lidocaine for Bier block. Future studies could focus on the use of other adjuvant treatments for lidocaine anesthesia for Bier block.

\section{Acknowledgments:}

Hereby, the authors express their thanks to the respected members of the Anesthesiology, Critical Care and Pain Management Research Center, Hormozgan University of Medical Sciences, Bandar Abbas, Iran, Dr. Elham Boushehri and Mohsen Azad, statistical consultants of this research and respected orthopedic operating room personnel working in Shahid Mohammadi Hospital, Bandar Abbas.

\section{Trial registration:}

The trial was registered at the Iranian Registry of Clinical Trials (http://www.irct.ir) with the Irct ID: IRCT2016052928158N1.

\section{Funding:}

The authors received financial support from Hormozgan University of Medical Sciences.

\section{Conflict of Interest:}

There is no conflict of interest to be declared.

\section{Authors' contributions:}

All authors contributed to this project and article equally. All authors read and approved the final manuscript.

\section{References:}

1) Amin A, Farooqui AK. Intravenous regional anaesthesia: Lidocaine versus combination of lidocaine and dexamethasone. Journal of Medical Sciences. 2012; 15(2): 123-27.

2) Sethi $D$, Wason R. Intravenous regional anesthesia using lidocaine and neostigmine for upper limb surgery. J Clin Anesth. 2010; 22(5): 324-8. doi: 10.1016/j.jclinane.2009.09.005. PMID: 20650377.

3) Yurtlu S, Hanci V, Kargi E, Erdogan G, Koksal BG, Gul S, et al. The analgesic effect of dexketoprofen when added to lidocaine for intraavenous regional anaesthesia: a prospective, randomized, placebocontrolled study. J Int Med Res. 2011; 39(5): 1923-31. doi: 10.1177/147323001103900537. PMID: 22117995.

4) Atef HM. Melatonin Versus Ketorolac as an Adjuvant in Lidocaine Intravenous Regional Anesthesia. Med J Cairo Univ. 2014; 82(1): 419-25.

5) Badeaux J, Bonanno L, Au H. Effectiveness of ondansetron as an adjunct to lidocaine intravenous regional anesthesia on tourniquet pain and postoperative pain in patients undergoing elective hand surgery: a systematic review protocol. JBI Database System Rev Implement Rep. 2015; 13(1): 27-38. doi: 10.11124/jbisrir-2015-1768. PMID: 26447005.

6) Jafarian AA, Imani F, Salehi R, Najd Mazaher F, Moini F. Simple Arm Tourniquet as an Adjunct to Double-Cuff Tourniquet in Intravenous Regional Anesthesia. Anesth Pain Med. 2016; 6(3): e29316. doi: 10.5812/aapm.29316. PMID: 27635387, PMCID: PMC5013696.

7) Choyce A, Peng P. A systematic review of adjuncts for intravenous regional anesthesia for surgical procedures. Can J Anaesth. 2002; 49(1): 32-45. doi: 10.1007/BF03020416. PMID: 11782326.

8) Khanna P, Arora M, Sunder R. Adjuvants for intravenous regional anaesthesia. Journal of Anaesthesiology Clinical Pharmacology. 2010; 26(3): 287-91.

9) Mir G, Naqeed A, Waani T, Shara A. Intravenous regional anesthesia with drug combination of lidocaine, ketamine and atracurium. The Internet Journal of Anesthesiology. 2008: 1.

10) Patacsil JA, McAuliffe MS, Feyh LS, Sigmon LL. Local Anesthetic Adjuvants Providing the Longest Duration of Analgesia for Single- Injection Peripheral Nerve Blocks in Orthopedic Surgery: A Literature Review. AANA J. 2016; 84(2): 95-103. PMID: 27311150.

11) Dexamethasone. The American Society of Health-System Pharmacists. Drugs.com. 2014. Available from: https://www.drugs.com/monograph/dexamethasone.html. 
12) Akram M, Farooqi FM, Irshad M, Faraz Ul Hassan S, Awais SM. Role of addition of Dexamethasone and Ketorolac to lignocaine intravenous regional anesthesia (Bier's Block) to improve tourniquet tolerance and post-operative analgesia in hand and forearm surgery. J Pak Med Assoc. 2015; 65(11 Suppl 3): S128-31. PMID: 26878503.

13) Sertoz N, Kocaoglu N, Ayanoglu HO. Comparison of lornoxicam and fentanyl when added to lidocaine in intravenous regional anesthesia. Braz J Anesthesiol. 2013; 63(4): 311-6. doi: 10.1016/j.bjan.2013.06.001. PMID: 23931243.

14) Bigat Z, Boztug N, Hadimioglu N, Cete N, Coskunfirat N, Ertok E. Does dexamethasone improve the quality of intravenous regional anesthesia and analgesia? A randomized, controlled clinical study. Anesth Analg. 2006; 102(2): 605-9. doi: 10.1213/01.ane.0000194944.54073.dd. PMID: 16428570.

15) Jankovic RJ, Visnjic MM, Milic DJ, Stojanovic MP, Djordjevic DR, Pavlovic MS. Does the addition of ketorolac and dexamethasone to lidocaine intravenous regional anesthesia improve postoperative analgesia and tourniquet tolerance for ambulatory hand surgery? Minerva Anestesiol. 2008; 74(10): 521-7. PMID: 18854793.

16) Hassani E, Mahoori A, Aghdashi MM, Pirnejad H. Evaluating the quality of intravenous regional anesthesia following adding dexamethasone to lidocaine. Saudi J Anaesth. 2015; 9(4): 418-21. doi: 10.4103/1658-354X.159467. PMID: 26543460, PMCID: PMC4610087.

17) Biradar PA, Kaimar P, Gopalakrishna K. Effect of dexamethasone added to lidocaine in supraclavicular brachial plexus block: A prospective, randomised, double-blind study. Indian J Anaesth. 2013; 57(2): 1804. doi: 10.4103/0019-5049.111850. PMID: 23825819, PMCID: PMC3696267.

18) Sinnott CJ, Cogswell III LP, Johnson A, Strichartz GR. On the mechanism by which epinephrine potentiates lidocaine's peripheral nerve block. Anesthesiology. 2003; 98(1): 181-8. doi: 10.1097/00000542200301000-00028. PMID: 12502995.

19) Choi S, Rodseth R, McCartney CJ. Effects of dexamethasone as a local anaesthetic adjuvant for brachial plexus block: a systematic review and meta-analysis of randomized trials. Br J Anaesth. 2014; 112(3): 42739. doi: 10.1093/bja/aet417. PMID: 24413428. 